Research, Society and Development, v. 9, n.1, e94911599, 2020

(CC BY 4.0) | ISSN 2525-3409 | DOI: http://dx.doi.org/10.33448/rsd-v9i1.1599

\title{
Masterchef Brasil: possibilidades de interatividade entre programa e telespectadores
}

Masterchef Brazil: possibilities of interactivity between program and viewers

Masterchef Brasil: posibilidades de interactividad entre programa y televisiones

Recebido: 04/92019 | Revisado: 10/09/2019 | Aceito: 02/10/2019 | Publicado: 11/10/2019

\section{Matheus Silveira Jardim}

ORCID: https://orcid.org/0000-0001-8245-5049

Universidade Franciscana, Brasil

E-mail: Silveira_m@outlook.com

Angélica Pereira Moreira

ORCID: https://orcid.org/0000-0002-3944-4878

Universidade Franciscana, Brasil

E-mail: angelica.pereira@ufn.edu.br

\section{Resumo}

Esta pesquisa tem como objetivo principal estudar as práticas do programa MasterChef BR da Rede Bandeirantes na tentativa de estabelecer interatividade com o usuário/telespectador. Como objetivos secundários, ficou definido: classificar o tipo de interação utilizado na $3^{\circ}$ temporada do programa MasterChef Brasil profissionais; identificar o nível de interatividade utilizado no programa; classificar as possibilidades de interação que são oferecidas no MasterChef BR a partir da integração da primeira tela com a plataforma digital Twitter; e ainda, comparar as possibilidades de interatividade entre o programa e Twitter. Para tanto, foi utilizado como metodologia à pesquisa qualitativa, exploratória e descritiva, a partir das técnicas de análise de conteúdo e observação indireta, a fim de compreender os dados obtidos na transmissão do programa no período de 21 de agosto a 11 de dezembro de 2018. Nas análises, constatou-se que embora o MasterChef seja interativo e busque fomentar a participação dos seus telespectadores, as ações do público são pré-determinadas a partir de possibilidades que são oferecidas pela produção do programa.

Palavras-chave: Convergência midiática; Interação; Segunda tela.

\section{Abstract}

This research has as main objective to study the practices of the program MasterChef BR da Rede Bandeirantes in the attempt to establish interactivity with the user / viewer. As 
secondary objectives, it was defined: to classify the type of interaction used in the third season of the program MasterChef Brazil professionals; identify the level of interactivity used in the program; Classify the interaction possibilities that are offered in MasterChef BR from the integration of the first screen with the digital platform Twitter; and compare the possibilities of interactivity between the program and Twitter. For that, a qualitative, exploratory and descriptive research was used as a methodology for this work, based on content analysis and indirect observation techniques, for the purpose of understand the data obtained during the transmissions of the programs from August 21 to December 11, 2018. In the analyzes, it was found that although the MasterChef is interactive and seeks to encourage the participation of its viewers, the actions of the public are predetermined from the possibilities that are offered by the production of the program.

Keywords: Media Convergence; Interaction; Second screen.

\section{Resumen}

Esta investigación tiene como objetivo estudiar las prácticas del programa Rede Bandeirantes MasterChef BR en un intento por establecer la interactividad con el usuario / espectador. Como objetivos secundarios, se definió: clasificar el tipo de interacción utilizada en la temporada 3 del programa MasterChef Brasil profesionales; identificar el nivel de interactividad utilizado en el programa; clasifica las posibilidades de interacción que se ofrecen en MasterChef BR desde la integración de la primera pantalla con la plataforma digital Twitter; y compare las posibilidades de interactividad entre el programa y Twitter. Para ello, se utilizó la investigación cualitativa, exploratoria y descriptiva como metodología, basada en análisis de contenido y técnicas de observación indirecta, para comprender los datos obtenidos de la transmisión del programa del 21 de agosto al 11 de diciembre de 2018. En el análisis, se encontró que aunque MasterChef es interactivo y busca alentar la participación de sus espectadores, las acciones del público están predeterminadas de las posibilidades que ofrece la producción del programa.

Palabras clave: Convergencia de medios; Interactividad; Segunda pantalla.

\section{Introdução}

Os meios de comunicação aliados às novas tecnologias provocam mudanças na sociedade e fazem surgir diferentes ferramentas de comunicação, que podem ser mediadas pelo celular, tablet, notebook e computador, nos quais possibilitam para as pessoas novos 
tipos de interações, inclusive para a televisão.

A televisão brasileira foi inaugurada oficialmente no dia 18 de setembro de 1950, em São Paulo, pelo jornalista Assis Chateaubriand, pioneiro da primeira emissora fundada no Brasil, a TV Tupi. Segundo Mattos (1990), desde então, a televisão passou por grandes transformações e aprimoramentos profissionais, causados pela evolução tecnológica e sociais de cada período. Entretanto, quando a televisão começou a ser utilizada no Brasil, praticamente não existiam aparelhos receptores, o que dificultou a visibilidade dos conteúdos que estavam sendo transmitidos, a partir disso, visando popularizar o veículo, Chauteaubriand mandou instalar alguns televisores em praça pública, no intuito de que as pessoas tivessem a oportunidade de assistir os primeiros programas (MATTOS, 1990).

Com o passar do tempo, a televisão foi se inserindo nas casas, provocando comentários e estimulando discussões a sua volta e, diante deste contexto, passou a fazer parte da comunicação estabelecida entre os indivíduos, pois o mais importante não é o que foi visto nela, mas sim o que as pessoas têm para falar a partir do que viram nela. Segundo o Mídia Dados (ONLINE, 2018), a projeção de domicílios com aparelhos de televisão chega a 97,3\%, ou seja, é o meio de comunicação com menor grau de exclusão social. Logo, entende-se que a TV tornou-se um objeto de companhia disponível em quase todos os lugares, tornando-se um veículo social para que as pessoas não se sintam sozinhas ou solitárias (WOLTON, 2007).

Com a chegada da Internet na década de 1990, Gabriel (2013) destaca que passamos a viver uma revolução que levou a sociedade a uma nova era: a digital. Nesta era, a televisão teve que se adaptar as tamanhas mudanças ocorridas e passou a fomentar e adotar cada vez mais o método de interação com seus telespectadores, de maneira que haja uma integração entre primeira tela, a televisão e a segunda tela, a internet. Segundo Sagrilo (2017), os recursos disponíveis na integração das telas são capazes de complementar a experiência do telespectador com cada meio apresentado, resultando no fortalecimento do conteúdo que está sendo veiculado.

Neste contexto, é perceptível que a forma de se produzir no meio televisual está em constante mudança por conta da convergência midiática que passou a existir entre os meios de comunicação, bem como pela interação, visto que a relação entre a televisão e a internet é capaz de proporcionar maior visibilidade, gerar fluxos de informações, relacionamentos e diálogos (SAGRILO, 2017), o que vai ao encontro do que Jenkins (2009) já dizia, que as mídias não morrem e não se substituem, elas colidem e se cruzam, e o que muda são as nossas relações com elas por conta das grandes transformações que acontecem em nossa sociedade. A partir de tantos avanços, principalmente da internet, os programas de televisão passaram a 
propor mais estratégias que possibilitassem maior espaço tanto para o seu telespectador quanto para aumentar a audiência.

Diante deste cenário, programas interativos foram ganhando espaço, ampliando as formas de interação e hoje em pleno século XXI, não tem como deixar de considerar a internet e a força dos prosumers na construção de programas de TV. As pessoas querem interagir, então isso precisa ser levado em conta e, portanto, as marcas/programas precisam se adaptar, criar novos formatos e estratégias para que isso aconteça.

Tais estratégias podem ser observadas em alguns programas televisivos, como por exemplo o "Você Decide", transmitido dos anos de 1992 a 2000, pela Rede Globo (S/D), quando ainda nem se pensava em convergência midiática. Este foi um dos primeiros programas a utilizar a estratégia de interação com seu telespectador, já que em cada episódio do programa eram simuladas diferentes situações e, ao final quem escolhia era o público através de votações via telefone fixo. Também, há o reality show Big Brother Brasil (BBB), da mesma emissora, que além de incentivar os usuários a votarem contra um participante via ligações, como acontecia no "Você Decide", possibilita também que a votação aconteça através do site oficial do programa e, ainda, incentiva os usuários na utilização de hashtags para comentar sobre tudo que acontece no BBB nas redes sociais.

Já o programa MasterChef Brasil, transmitido pela Rede Bandeirantes, é um exemplo mais recente de como as organizações podem se inserir no mundo das mídias sociais. $\mathrm{O}$ programa se divide em três subcategorias: o amador, kids e profissionais. O MasterChef Amador teve seu início em 2014 e já esta em sua $6^{\circ}$ temporada, enquanto o MasterChef Kids estreou em 2015, sendo esta a única temporada. Já o MasterChef Profissionais iniciou em 2016, e já conta com 3 temporadas produzidas, sendo a última em 2018 (BAND, 2018)

O programa além de ser transmitido em um canal de TV aberta, está inserido no âmbito digital e vem ganhando destaque nesta ambiência, já que anunciou em sua $2^{\circ}$ e $5^{\circ}$ temporada amadora o nome do vencedor, em primeira mão, nas plataformas Twitter e Instagram, respectivamente, antes mesmo de anunciar na TV.

Ainda referente a temporada amadora do programa MasterChef Brasil, segundo o Mídia Dados (2017, ONLINE), no Twitter, a \#MasterChefBR, hashtag oficial do programa em sua $4^{\circ}$ temporada foi mencionada mais de 671 mil vezes, ficando em $2^{\circ}$ lugar nos trend topics brasileiros por 7 horas. Nesta final do programa, a Folha de São Paulo (2017) registrou aproximadamente 5 milhões de tweets e foi líder de audiência do horário com dez pontos no Ibope por 51 minutos (cada ponto equivale a 199,3 mil espectadores, totalizando uma média de 1 milhão e 993 mil telespectadores). 
O programa, que é considerado como talent show, gênero de programa televisivo no qual os participantes competem através de suas habilidades em determinada área (SILVA, 2015), utilizou-se de estratégias de interação e relacionamento com os espectadores, tornandose um exemplo de atuação na plataforma digital Twitter.

Segundo entrevista para o jornal O DIA, a apresentadora do talent show, Ana Paula Padrão diz que:

As Redes sociais são muito importantes para a consolidação da audiência de qualquer programa de TV, principalmente na TV aberta. Quando falávamos, no passado, da convergência de plataformas, era isso que eu esperava. Colaboração e não competição entre elas. Usando o Twitter enquanto assistem ao 'MasterChef', os telespectadores podem participar mais, interagir, comentar e sentir-se parte do produto (Padrão, 2015).

Considerando tamanha repercussão do programa, é evidente que este cenário favorece ao investimento das marcas. Segundo reportagem do jornal Meio e Mensagem (2017), mais de 40 marcas já anunciaram no Masterchef Brasil desde a sua primeira edição em 2014. Tais estratégias e tamanha visibilidade incentivaram a existência e interação do programa com seus fãs e/ou fandoms, como são chamadas as comunidades de seguidores, que de acordo com Jenkins (2009) é a representação de uma comunidade ou coletivo de fãs unidos pelo gosto em comum referente à determinada figura.

Visto então, de que estamos inseridos e vivendo em uma era de convergência midiática e o interesse dos pesquisadores pela temática e pelo programa televisual, justifica-se a importância do presente projeto o fato das marcas estarem percebendo que precisam se aproximar e interagir com os seus telespectadores, havendo então a integração entre primeira tela com a segunda tela. Em função disso é importante refletir o uso das práticas comunicacionais, para traçar como isso acontece e quais são os melhores resultados. Compreendemos que as estratégias comunicacionais utilizadas pelo programa para se inserir em outras mídias sociais, agregam pontos positivos para o campo da comunicação, já que com os resultados será possível deixar em evidencia o conhecimento sobre o tema e suas possibilidades, que serão uteis para quem quiser saber mais sobre formas interativas.

A partir do contexto até aqui apresentado, estabeleceu-se a seguinte problemática para o referido estudo: Quais são as práticas estabelecidas pelo programa MasterChef BR que oferecem interatividade com os seus usuários/telespectadores? Dessa forma, o objetivo geral foi estudar as práticas do programa MasterChef BR na tentativa de estabelecer interatividade com o usuário/telespectador. Os objetivos específicos são classificar o tipo de interação utilizado na $3^{\circ}$ temporada do programa MasterChef Brasil profissionais; identificar o nível de 
interatividade utilizado na $3^{\circ}$ temporada do programa; classificar as possibilidades de interação que são oferecidas na $3^{\circ}$ temporada do programa MasterChef Brasil a partir da integração da primeira tela com a plataforma digital Twitter; encontrar no MasterChef Profissionais as possibilidades de interação que o Twitter oferece.

\section{Cultura participativa em espaços interativos}

Tendo em vista que o objetivo desta pesquisa foi estudar as práticas do programa MasterChef $\mathrm{BR}$ na tentativa de estabelecer interatividade entre o programa com os telespectadores, foi importante partir do cenário atual que os meios se encontram, ou seja, de que vivemos um período de migração digital causado pelas múltiplas plataformas digitais, onde os meios encontram-se cada vez mais integrados. Esta mudança é chamada de convergência midiática, que segundo Jenkins (2009) está relacionada com as transformações tecnológicas, mercadológicas e culturais que de alguma forma afetam as mídias e as relações entre os seres humanos. Por convergência entende-se, que o fluxo de conteúdo acontece através das variadas plataformas de mídia e pela mudança de comportamento dos públicos dos meios de comunicação, que vão em busca das experiências de entretenimento que desejam, fomentando que os conteúdos e informações passem a circular por diferentes mídias e com ativa participação dos telespectadores, consumidores ou usuários (JENKINS, 2009).

Neste sentido, as participações ativas de usuários podem ser vistas como uma cultura participativa, termo este que diverge das noções que existem sobre a passividade dos telespectadores quanto aos meios de comunicação. "É a cultura em que fãs e outros consumidores são convidados a participar ativamente da criação e da circulação de novos conteúdos" (JENKINS, 2009, p. 378).

\footnotetext{
Em vez de falar sobre produtores e consumidores de mídia como ocupantes de papéis separados, podemos agora considera-los como participantes interagindo de acordo com um novo conjunto de regras, que nenhum de nós entende por completo. Nem todos participantes são criados iguais. Corporações - e mesmo indivíduos dentro das corporações de mídia - ainda exercem maior poder do que qualquer consumidor individual, ou mesmo um conjunto de consumidores. E alguns consumidores têm mais habilidades para participar dessa cultura emergente do que outros (JENKINS, 2009, p. 30).
}

Sendo assim é preciso estar atento às mudanças comunicacionais existentes, a fim de adequar-se ao novo comportamento da sociedade, e ainda, participar dos novos canais de interatividade nos quais o consumidor está inserido (LAS CASAS, 2010). Nesta mesma linha de raciocínio, Barichello (2014) ressalta que existe uma lógica midiática na qual o digital 
possibilita maior participação aos seus usuários, que passam a produzir conteúdo e a ocupar espaços, que antes eram referentes ao sistema midiático e, portanto, tinham características do emissor.

A emergência de novos espaços de interação, especialmente nos suportes digitais, amplia as possibilidades de resposta e interpretação dos interagentes. Mais do que isso, as tecnologias digitais ampliam as possibilidades de proposição, pois não se trata apenas de um sujeito receptor, mas de um sujeito que possui condições de construir seus próprios espaços de atuação e, dessa forma, colocar em debate questões de seu interesse (BARICHELLO, 2014, p. 6).

No século XXI, o crescimento da internet tornou-se essencial para compartilhar gostos, oferecendo ainda mais espaço para a interação de fãs com os programas de entretenimento exibidos em canais abertos ou fechados. Neste contexto, as velhas e novas mídias se mostram semelhantes, e o poder do produtor de mídia e o poder do consumidor interagem de maneiras imprevisíveis (JENKINS, 2009).

Segundo Carneiro (2012) a consolidação da internet e o uso de dispositivos móveis enquanto se assiste a algum programa televisivo é o que caracteriza o fenômeno intitulado como segunda tela. As telas possuem tamanhos variados que condizem com a função para qual foram criadas, e com o tipo de relação que cada uma possui com seus usuários. A variedade e localização das telas crescem a cada dia, e, portanto, podem estar na casa dos usuários (através do televisor ou PC), acompanhar o usuário para aonde ele for (pelo celular, laptop ou tablet), em automóveis (GPS ou televisor portátil) ou até mesmo em lugares públicos (estações de ônibus, barzinhos e etc.) (CARNEIRO, 2012).

$\mathrm{Na}$ sociedade moderna, este hábito tornou-se comum para criar novas formas de participação e de gerar conteúdo. A segunda tela, por exemplo, permite que a pessoa amplie a experiência de contato primário com um meio através de um segundo dispositivo, neste caso a TV com a internet, potencializando a interpretação e o alcance de determinado conteúdo no momento em que está sendo consumido. Para Fechine et.al (2013) segunda tela é:

\footnotetext{
Uma expressão que designa a oferta de conteúdos interativos complementares, e preferencialmente sincronizados, com a programação por meio de aplicativos desenvolvidos para tablets e smartphones, por exemplo. Esses dispositivos têm sido usados também para estender virtualmente a “conversa do sofá" em torno dos programas, a partir da articulação da TV com as redes sociais (FECHINE, et.al, 2013, p. 21)
}

A pesquisa realizada pelo IBOPE Conecta (2015), sobre o comportamento do internauta brasileiro, revelou que $88 \%$ dos internautas assistem TV e acessam internet ao mesmo tempo. O smartphone é o dispositivo mais usado (65\%), seguido do computador $(28 \%)$ e do tablet (8\%). De acordo com o mesmo levantamento, redes sociais são acessadas 
por $72 \%$ dos telespectadores que recorrem à internet simultaneamente. A pesquisa sobre os dispositivos utilizados para navegar na internet ou acessar as redes sociais é de 2015 e, portanto, em 2019 essa porcentagem já deve ser maior.

$\mathrm{Na}$ internet, as redes sociais possuem elementos que as caracterizam, que segundo Recuero (2009), destacam-se os atores sociais, que são os primeiros elementos da rede social que representam laços, estes significam as pessoas envolvidas na rede que está sendo analisada. Entretanto, assim como na comunicação feita através de um celular, tablet, notebook ou por um computador, as pessoas não são percebidas imediatamente, pois trabalhase com representações de atores sociais, ou seja, com os espaços de interação, lugares de fala e construídos por pessoas para se expressarem nas redes/internet.

Dentre as redes sociais, o Twitter, criado em 2006, foi a primeira a ter relação com a segunda tela. Segundo Recuero (2009), cada usuário se apropria da ferramenta de maneira diferenciada, sobretudo a utiliza para socialização e busca por informações. O Twitter é uma rede social bastante peculiar, mais especificamente denominada microblogging, que permite aos usuários enviar e receber atualizações pessoais de outros contatos (em textos de até 280 caracteres, conhecidos como "tweets"), por meio do site de serviço, por SMS e por softwares específicos de gerenciamento (STRUTZEL, 2015). Segundo Torres (2009, p.149) "o nome foi inspirado em um pássaro que, para manter outros pássaros informados do que está fazendo e onde está, emite periodicamente um trinado estridente".

Sendo assim, através desta plataforma digital, é possível interagir com outros usuários por meio das possibilidades que a rede social oferece, tais como: twittar; iniciar uma conversa na caixa de tweets; dar follow ou unfollow; responder; retwittar; favoritar; criar enquetes; utilizar hashtags; mencionar; enviar direct; criar um momento ou uma lista e também enviar sua localização, conforme ilustra o quadro 1. "Dado o grande fluxo de postagens (tweets) e de usuários, o Twitter tornou-se um instrumento importante para elucidar opiniões da audiência" (SAGRILO, 2017, p. 152). Segundo Strutzel (2015), completa que esta rede social foi uma das primeiras a utilizar as hashtags para demarcar assuntos específicos e essa prática se expandiu bastante, a ponto de ser adotada por outras plataformas de redes sociais.

Quadro 1: Interatividade que o Twitter oferece

\begin{tabular}{|l|l|}
\hline Twittar; & Você poderá escrever o que está pensando em até 280 caracteres. \\
\hline $\begin{array}{l}\text { Iniciar uma conversa na } \\
\text { caixa de tweet; }\end{array}$ & $\begin{array}{l}\text { A partir de um post de outra pessoa, o usuário poderá comentar aquele } \\
\text { tweet ao invés de retwittar. }\end{array}$ \\
\hline Dar follow ou unfollow; & $\begin{array}{l}\text { Você poderá dar follow (seguir) qualquer pessoa que você tenha } \\
\text { interesse e ter acesso aos seus conteúdos, ou simplesmente dar } \\
\text { unfollow (deixar de seguir) e não ter mais acesso ao que essa pessoa }\end{array}$ \\
\hline
\end{tabular}


Research, Society and Development, v. 9, n.1, e94911599, 2020

(CC BY 4.0) | ISSN 2525-3409 | DOI: http://dx.doi.org/10.33448/rsd-v9i1.1599

\begin{tabular}{|c|c|}
\hline & posta. \\
\hline Responder tweets; & $\begin{array}{l}\text { Em qualquer momento você poderá responder algum tweet, seja ele } \\
\text { para você ou apenas do seu interesse em responder. }\end{array}$ \\
\hline Retwittar; & O usuário poderá compartilhar (retwittar) o tweet de outra. \\
\hline Favoritar; & $\begin{array}{l}\text { Está opção permite que o usuário curta (favorite) o tweet de outra } \\
\text { pessoa. }\end{array}$ \\
\hline Criar enquetes; & $\begin{array}{l}\text { É possível a criação de enquetes por parte dos usuários, com o máximo } \\
\text { de até quatro opções para a resposta. O usuário também poderá definir } \\
\text { a duração da enquete, que pode durar até uma semana. }\end{array}$ \\
\hline Utilizar Hashtag; & $\begin{array}{l}\text { O uso de hashtag ajudará na segmentação de sua busca, portanto você } \\
\text { chegará direto aqueles tweets que utilizaram a hashtag que você } \\
\text { procura. }\end{array}$ \\
\hline User/mencionar; & Através de um @ o usuário pode mencionar o user do seu follow. \\
\hline Direct; & $\begin{array}{l}\text { O usuário poderá mandar mensagens diretas para quem quiser. Neste } \\
\text { caso, só a pessoa que enviou e recebeu terá acesso à mensagem. }\end{array}$ \\
\hline Criar um momento; & $\begin{array}{l}\text { Nesta função, as pessoas vão poder criar seu momento (uma notícia), } \\
\text { das mais variadas temáticas e compartilhar para quem quiser ver. O } \\
\text { objetivo desta função é ajudar os usuários a encontrar os } \\
\text { acontecimentos mais importantes na rede social, em tempo real. }\end{array}$ \\
\hline Lista; & $\begin{array}{l}\text { É um grupo de usuários da rede social escolhido a dedo. Você pode } \\
\text { criar sua própria ou se inscrever em listas criadas por outras pessoas, } \\
\text { isso possibilitará ver os tweets somente daquelas pessoas que você } \\
\text { escolher. }\end{array}$ \\
\hline Localização; & usuário pode colocar sua localização. \\
\hline
\end{tabular}

Fonte: Elaboração própria com base no Twitter.

Com tamanha repercussão, a rede social geralmente é tida como aliada pela televisão, já que os usuários a utilizam para comentar o que assistem em tempo real. Isso vai ao encontro com o que Tunstill (2016) disse em reportagem a GAÚCHAZH, de que as pessoas assistem TV por diferentes razões, sendo uma delas, a razão social. "O ser humano gosta da humanidade, de ser sociável, então as pessoas gostam de assistir à TV juntas. A maior parte de consumo da televisão e de vídeo ocorre por meio da TV ao vivo, e a razão por trás disso é humana: gostamos de compartilhar". Assim, os telespectadores/usuários assistem e comentam o que estão acompanhando, no Twitter e/ou no Facebook, gerando conteúdo para os programas televisivos, além do contato virtual com outras pessoas.

Segundo Oliveira (2010), o poder de criar e transmitir conteúdos não são mais um privilégio exclusivo da mídia, mas também, dos consumidores anteriormente vistos como passivos, e que hoje são considerados como atuantes nas redes sociais. Desta forma, isso tudo representa o que Jenkins (2009) caracteriza como cultura de participação. Adquirir a fidelidade do telespectador é essencial para a conquista do sucesso e da cultura participativa, pois a interação do público na internet irá gerar novos conteúdos sem fins lucrativos, além de acontecer a integração entre as telas.

A partir desta perspectiva, o modo de se produzir e assistir TV mudou com a chegada da internet. A evolução da televisão está associada a necessidade que a mesma possui de se 
moldar as transformações causadas pelo avanço da tecnologia, dos telespectadores e do mercado. Diante destas mudanças, o telespectador passou a receber mais possibilidades de conteúdo através de estratégias que possibilitem ao usuário uma participação mais ativa e de controle sobre o meio, ocorridas por conta de um ritmo cada vez mais acelerado (CARNEIRO, 2012). Sendo assim, cabe entender mais sobre o papel da TV interativa e de que forma ela estabelece um papel interativo entre outros meios de comunicação as pessoas.

\subsection{A interatividade da TV}

No contexto da convergência tecnológica, o audiovisual também converge linguagens e tem ampliado suas possibilidades de produção, distribuição, usos e consumos (TEIXEIRA, 2008). Segundo Montez e Becker (2005), as mudanças ocorridas na TV digital não se resumem apenas à qualidade e otimização de sua imagem, mas sim de outras vantagens que são satisfatórias para o técnico e social, sendo uma delas: a interatividade.

A interatividade na televisão atribui a audiência uma maior participação, envolvimento e colaboração, tanto sobre o aparelho televisivo como na veiculação de conteúdos. Este contexto estabeleceu mudanças na forma como os telespectadores consomem e agem com as informações que estão recebendo através de seus aparelhos, indicando novos modelos que alteram a imagem do telespectador antigamente visto como passivo.

Para tal compreensão dos termos adotados na presente pesquisa, cabe fazer uma diferenciação entre interação de interatividade. Para Montez e Becker (2005, p. 33) "a interação pode ocorrer diretamente entre dois ou mais entes atuantes, ao contrário da interatividade, que é necessariamente intermediada por um meio eletrônico". Tal definição pode ser complementada com teorias que Stauer (1992) estabeleceu anteriormente, de que a interação é vista como um modelo para toda comunicação interativa, enquanto a interatividade se refere ao grau em que os telespectadores de um meio podem influenciar a forma ou o conteúdo veiculado em um ambiente televisivo.

Quando pensamos em interatividade nos meios de comunicação, podemos classificalas em meios quentes e meios frios. Segundo McLuhan (1964) os meios quentes são os que permitem pouco ou nada da participação e intervenção de usuários. Já os meios frios se diferenciam por assumir a participação dos usuários, estimulando o desejo de interagir, como a televisão faz. Neste sentido, os meios frios possibilitam aos seus usuários que eles se sintam à vontade e motivados a interagir no espaço que lhe foi concedido. É o que ocorre com a TV interativa, pois é necessário que haja participação e o interesse dos telespectadores e da 
própria emissora na produção de conteúdos.

Para melhor compreender o conceito de interatividade, ainda é possível classificá-la em três níveis, em ordem crescente de alcance e importância: reativo, coativo e pró-ativo (REISMAN, 2002 apud MONTEZ; BECKER, 2005, p. 35). O quadro 2 apresenta as principais características de cada nível:

Quadro 2: Tipos de interação

\begin{tabular}{|c|l|}
\hline Reativa & $\begin{array}{l}\text { Nesse nível, as opções e feedbacks são dirigidos pelo programa, havendo pouco } \\
\text { controle do usuário sobre a estrutura do conteúdo. }\end{array}$ \\
\hline Coativa & Há possibilidades do usuário controlar a sequência, o ritmo e o estilo do conteúdo. \\
\hline Pró-ativa & O usuário pode controlar tanto a estrutura quanto o conteúdo. \\
\hline
\end{tabular}
Fonte: Reisman (2002) apud Montez e Becker (2005, p. 35).

Primo (2000) ainda ressalta que, além dos três níveis citados por Reisman (2002) apud Montez e Becker (2005, p. 35), a interatividade pode ocorrer por meio de mais dois níveis: 1) interação reativa e 2) interação mútua. $\mathrm{Na}$ interação reativa, as respostas e escolhas dos usuários já estão pré-determinadas, ou seja, as opções disponíveis são decidias pela emissora e o telespectador opta dentre as opções ofertadas. Enquanto na interação mútua a comunicação se altera nos papéis de emissor e receptor, permitindo que haja possibilidade de interferência na locução de um outro usuário. Portanto há mais liberdade no processo comunicativo desta opção, o que não acontece na interação reativa.

\begin{abstract}
[...] pode-se dizer que a interação mútua se caracteriza como um sistema aberto, enquanto a interação reativa se caracteriza como um sistema fechado. A interação mútua forma um todo global. Não é composto por partes independentes; seus elementos são interdependentes. Onde um é afetado, o sistema total se modifica. O contexto oferece importante influência ao sistema, por existirem constantes trocas entre eles. Por conseguinte, os sistemas interativos mútuos estão voltados para a evolução e desenvolvimento. E por engajar agentes inteligentes, os mesmos resultados de uma interação podem ser alcançados de múltiplas formas, mesmo que independente da situação inicial do sistema (PRIMO, 2000, p.7).
\end{abstract}

No âmbito comunicacional, a TV é vista como um simples emissor de informações, no qual o telespectador é o receptor que recebe a mensagem através do canal. A interação descrita por Lévy (1999, p. 79), diz que "mesmo sentado na frente de uma televisão sem controle remoto, o destinatário decodifica, interpreta, participa, mobiliza seu sistema nervoso de inúmeras maneiras, e sempre de forma diferente de seu vizinho".

Devido ao crescimento e enfoque da pesquisa para a televisão, a partir dos conceitos do teórico André Lemos (1997, p. 1-2), é possível classificar a interatividade deste meio em quatro estágios de interação baseados na evolução tecnológica que esta mídia vem 
proporcionando ao longo dos tempos, conforme mostra o quadro 3.

Quadro 3: Níveis de interação

\begin{tabular}{|c|l|}
\hline Nível 0 & $\begin{array}{l}\text { Neste nível a TV funciona em preto e branco, com apenas um ou dois canais. A } \\
\text { interatividade aqui ocorre pela ação de ligar ou desligar o aparelho, regular volume, } \\
\text { brilho ou contraste. Com apenas dois canais, ainda é possível apenas acrescentar a } \\
\text { possibilidade de mudar para outra emissora. }\end{array}$ \\
\hline Nível 1 & $\begin{array}{l}\text { Neste nível a televisão ganha cores, outras emissoras e controle remoto - conhecido } \\
\text { como zapping, que antecede a navegação contemporânea na web. Esta fase deu certa } \\
\text { autonomia ao telespectador. }\end{array}$ \\
\hline Nível 2 & $\begin{array}{l}\text { Neste nível alguns equipamentos periféricos se unem à televisão, como por exemplo: o } \\
\text { videocassete, as câmeras portáteis e os jogos eletrônicos. O telespectador ganha novas } \\
\text { tecnologias para utilizar junto a televisão, podendo agora também ver vídeos, jogar, } \\
\text { gravar programas e vê-los ou revê-los quando quiser. }\end{array}$ \\
\hline Nível 4 & $\begin{array}{l}\text { Neste nível surgem alguns sinais da TV interativa com características digitais. O público } \\
\text { pode interferir no conteúdo emitido a partir de telefone, fax, correio eletrônico ou e-mail, } \\
\text { como ocorria no programa 'Você Decide' da Rede Globo. }\end{array}$ \\
$\begin{array}{l}\text { Neste nível surge a chamada "televisão interativa”, que permite a participação do } \\
\text { telespectador em um conteúdo televisivo, por meio de um conjunto de tecnologias que } \\
\text { possibilitam a comunicação à distância. O que permite, por exemplo: a escolha de } \\
\text { ângulos, câmeras, diferentes encaminhamentos das informações, etc. }\end{array}$ \\
\hline
\end{tabular}

Fonte: Lemos (1997, p. 1-2).

Montez e Becker (2005) acreditam que a TV interativa não se trata apenas da junção ou convergência da internet com a TV, tão pouco da evolução das mesmas, mas sim de uma nova mídia que engloba ferramentas de várias outras. Neste sentido, a partir da definição de Lemos (1997) sobre os níveis, é possível perceber que há necessidade de mais três estágios ilustrados no quadro 4, que são sugeridos por Montez e Becker (2005, p. 36) e que podem vir a representar a nova mídia.

Quadro 4: Níveis de interação

\begin{tabular}{|c|l|}
\hline Nível 5 & $\begin{array}{l}\text { Neste nível o telespectador passa ter uma presença mais efetiva no conteúdo, saindo da } \\
\text { restrição de apenas escolher as opções definidas pelo transmissor. O usuário poderá } \\
\text { participar da programação enviando vídeo de baixa qualidade, que pode ser feito através } \\
\text { de uma webcam ou filmadora analógica. }\end{array}$ \\
\hline Nível 6 & $\begin{array}{l}\text { A largura de banda nesse canal aumenta, no qual passa a oferecer possibilidades de envio } \\
\text { de vídeos em alta qualidade, semelhante ao que é transmitido pela emissora. Dessa } \\
\text { forma, a interatividade chega a um nível muito superior à reatividade, como acontece no } \\
\text { nível quatro de Lemos (1997). }\end{array}$ \\
\hline Nível 7 & $\begin{array}{l}\text { A interatividade plena é atingida nesse nível. O telespectador confunde-se com o } \\
\text { transmissor, sendo assim possível gerar conteúdo. Este nível se assemelha ao que ocorre } \\
\text { hoje na internet, onde qualquer um pode criar sites, necessitando apenas ferramentas } \\
\text { básicas e adequadas. O mesmo telespectador ainda produz programas e os envia à } \\
\text { emissora, então rompendo um tradicional monopólio de produção e veiculação que } \\
\text { conhecemos hoje. }\end{array}$ \\
\hline
\end{tabular}

Fonte: Montez e Becker (2005, p .36). 
A TV interativa surgiu como uma nova oportunidade para os telespectadores que sempre quiseram exercer um papel mais ativo frente às programações televisuais. $\mathrm{O}$ avanço tecnológico causado pelo meio televisual e computacional proporcionam diferentes possibilidades de produtos midiáticos em relação à forma do agir interativo (MONTEZ; BECKER, 2005). Neste sentido, além da participação mais ativa do usuário servir como um feedback daquilo que está sendo transmitido, a maior diferença da TV interativa está no envolvimento emocional que as pessoas criam com a transmissão dos conteúdos (TEIXEIRA, 2008). Segundo Silvana Pazin, diretora de mídia do Grupo de Contas da OpusMúltipla, em entrevista para o site negócios RPC:

Enquanto a TV atinge a grande massa, o digital contribui para impactar o público que está fragmentado em outras áreas de interesse. É o que chamamos de cauda longa. Quando integramos o conteúdo digital, ampliamos ainda mais a visibilidade proporcionada pela TV, com impactos qualificados e direcionados a públicos mais específicos (PAZIN, 2017, ONLINE).

A partir desta perspectiva da TV interativa, o telespectador passa a encontrar nos dispositivos digitais um meio para comunicar os sentidos, ao mesmo tempo em que está consumindo um conteúdo televisivo. As emissoras passaram a convidar os telespectadores a participarem dos programas, através de hashtags, ligações, vídeos, enquetes, comentários, e assim, participar da TV tradicional a partir da segunda tela, tornando cada vez mais presente a interação do público que está nas redes sociais com a TV.

\subsection{Estratégias de integração de telas}

Cada vez mais o público que consome TV, tem se inserido nos meios digitais. Os meios se adaptaram a essa nossa era e, diante deste contexto, se evidencia o crescimento do fenômeno intitulado como segunda tela, tal como um estimulo para o usuário interagir cada vez mais com a programação, implicando na criação de estratégias que sustentem esse novo cenário. Para isso, Sagrillo (2017, p. 109) contextualizou em sua tese de doutorado 12 estratégias visíveis que vem sendo utilizadas para integrar as telas, que são elas:

a) Convite ao acesso a ambientes - neste item, os apresentadores de programas televisivos transmitem informação ao telespectador ou usuário em tempo real da veiculação do conteúdo. Além disso, ainda permite que o telespectador execute ações ou disponibilize conteúdos complementares aos que estão sendo transmitidos no momento. Neste sentido, o telespectador é convidado para acessar ambientes online, que possuem diversas ordens e 
finalidades para ofertar mais conteúdo ou outras possibilidades de programação, tais como: informações gerais, notícias, bastidores e episódios extras. Ou até mesmo, para solicitar o envio de conteúdos ao público, sendo eles de: natureza sonora, imagética ou fotográfica, e assim então, gerar mais engajamento a partir de promoções, enquetes e concursos.

b) Conexão com redes sociais digitais - esta estratégia refere-se a como aproveitar tudo o que a segunda tela oferece, possibilitando deixar a posição reativa para assumir um papel de grande influência no mundo on-line. Neste sentido, os canais de TV passaram a dialogar com a audiência em tempo real, através das redes sociais, "liderando e pautando as discussões sobre a programação, o que permite curadoria de conteúdo ao vivo ou, até mesmo, o estímulo às votações" (SAGRILLO, 2017, p. 110). Entretanto, Sagrillo (2017) diz que o maior desafio das emissoras de TV brasileira é manter a atenção do público que está engajando nas redes sociais e, neste sentido, os canais passaram a interagir cada vez mais com seus seguidores, a partir de postagens interativas e outras curiosidades que surgem no decorrer dos programas. Tal estratégia possibilita que os telespectadores se sintam ativos e na liberdade de compartilhar suas opiniões e interpretações sobre aquilo que assistem na TV, em suas redes sociais, passando a integrar não somente as telas, mas os conteúdos também.

c) Disponibilização de chats on-line - o chat funciona como uma conversação a fim de debater sobre determinados assuntos. Neste sentido, o conteúdo do chat que foi transmitido na televisão poderá ser compartilhado novamente, agora nas redes sociais, expandindo o alcance da informação. Segundo Sagrillo (2017, p. 111) "o mesmo acontece com as emissoras, quando, principalmente no final de exibição, anunciam o desdobramento daquele programa na rede social, possibilitando a continuidade da discussão".

d) Apelo a hashtag - é evidente que o uso de hashtag vem aumentando e, agradando os programas televisivos que já a utilizam como uma estratégia de levar seus conteúdos para as redes sociais, onde é considerada um caminho (ou até mesmo uma palavra-chave) para encontrar determinados assuntos divulgados por outros usuários nos espaços digitais. Grande parte dos programas possuem a sua própria hashtag, na maioria das vezes indicada na parte inferior da tela, ou anunciada pelo próprio apresentador no intuito de levar os telespectadores para as redes sociais, comentando e delimitando o assunto com a utilização da hashtag oficial. Neste sentido, ela ainda dará maior visibilidade ao programa, que poderá chegar aos Trending Topics do Twitter caso se torne o assunto mais comentado.

e) Oferta de avatares - são imagens que representam o perfil que um usuário utiliza nas redes sociais, jogos, simuladores ou fóruns, representando o seu corpo virtual. De acordo com Bélisle e Bodur (2010) as imagens referem-se a avatares, que servem para refletir 
detalhes da personalidade de quem os criou.

f) Disponibilização de aplicativos - segundo Sagrillo (2017, p. 114) “os aplicativos são recursos desenvolvidos pela indústria do entretenimento audiovisual e por profissionais da computação para proporcionar uma experiência de envolvimento entre telespectadores/usuários e programas de televisão". Neste sentido, com o crescimento do consumo de televisão e internet, as emissoras passaram a investir na estratégia de criação de aplicativos móveis para auxiliar na sincronização dos programas.

g) Oferta de check-in dos programas - é uma ferramenta que possibilita o telespectador anunciar o conteúdo televisual que está consumindo, em suas redes sociais ou em aplicativos próprios para isso. Geralmente é compartilhado em tempo real da transmissão do programa, ficando visível para outros amigos da rede social e para discussão e opinião referente ao assunto abordado.

h) Criação de enquetes - a partir da interação com os telespectadores, as emissoras passaram a oferecer aos usuários a possibilidade de votação em enquetes com conteúdos relacionados ao que está sendo transmitido na televisão. Neste sentido, as emissoras estão convidando os telespectadores durante o programa a participar votando na web.

i) Proposta de desafios - esta estratégia consiste nos desafios que são propostos durante a transmissão de um programa, que tem como intuito promover a interatividade entre emissora, programa e telespectador.

j) Criação de concursos - são concursos criados na tentativa de aproximar e fazer com que o telespectador participe das produções televisivas.

k) Disponibilização de compras on-line - sempre haverá algum produto, acessório, roupa, maquiagem, que o telespectador irá desejar assistindo alguma das produções televisivas. Neste sentido, as emissoras passaram a utilizar uma ferramenta online capaz de suprir este desejo das pessoas: as lojas virtuais. A partir desta ferramenta, o telespectador poderá consumir pela internet aquilo que desejou através da televisão.

1) inserção de espaços interativos - "alguns programas estão inserindo espaços fixos ou em situações especiais como finais de temporadas, nomeadas de 'sala de interatividade' ou 'estúdio interativo', no interior dos programas para realizar ações específicas com os telespectadores/usuários" (SAGRILLO, 2017, p. 121). Tais ações costumam acontecer com a participação de influencers, youtubers ou famosos num geral, que estão inseridos nas redes sociais e em interação com seus seguidores.

Diante deste contexto, Sagrillo (2017) acrescenta que, de maneira geral, as possibilidades de interatividade têm como intenção garantir a satisfação dos telespectadores 
sobre os conteúdos apresentados. Além de, ainda, evidenciar o poder que o telespectador adquiriu ao longo do tempo, se mostrando ativo e capaz de opinar em suas redes sociais. As emissoras de TV já compreenderam a força que o digital possui e, portanto, começaram a migrar seus conteúdos para outras plataformas. É preciso conhecer as tendências, compreender o momento atual para, então, adaptar-se à realidade.

\section{Metodologia}

Quanto a natureza, tratou-se de uma pesquisa qualitativa, na qual "a finalidade primeira da pesquisa não é mostrar opiniões ou pessoas; ao contrário, pretende explorar o espectro de opiniões e as diferentes representações sobre o assunto em estudo" (MICHEL, 2015, p.40). A partir desta perspectiva, foi possível analisar dados que foram obtidos a partir de uma situação abordada pelos autores, e neste sentido, a pesquisa esteve voltada a avaliar os dados sem focar em quantificações.

Para maior embasamento teórico foi utilizada a pesquisa exploratória que segundo Michel (2015) é a fase inicial da pesquisa, na qual se busca fazer um levantamento bibliográfico sobre o tema, a fim de identificar informações e subsídios para definição dos objetivos. E ainda, foi utilizada a pesquisa descritiva que segundo Gil (1991, p. 28) tem como objetivo a "descrição das características de determinada população, fenômeno ou o estabelecimento de relações entre variáveis". Neste sentido, esta pesquisa é bastante utilizada para explicar, descrever e verificar problemas ou fenômenos da vida real (MICHEL, 2015).

Quanto a técnica, foi utilizada a análise de conteúdo, a fim de classificar as práticas de interatividade com seus telespectadores, níveis e características do programa MasterChef Brasil. Segundo Bardin (1977, p. 37), a análise de conteúdo "visa obter através de procedimentos sistemáticos e objetivos de descrição do conteúdo das mensagens, indicadores que permitam a inferência de conhecimentos relativos às condições de produção/recepção (variáveis inferidas) destas mensagens". Esta técnica de pesquisa é adequada para analisar personalidades, avaliar textos escritos, intenções, conteúdo das mensagens, propagandas, campanhas, discursos, obras literárias, entre outros (MICHEL, 2015).

Esta pesquisa também utilizou a técnica de observação indireta, que segundo Michel (2015, p.83) é "quando os dados são obtidos indiretamente e não são extraídos diretamente de pessoas, via entrevistas, questionários ou observações. São obtidos de documentos pessoais ou institucionais, material gráfico, quadros, tabelas [...] quaisquer formas de transmissão de informação". Ainda conforme Michel (2015), esta técnica acontece através da análise 
documental, que se dá pela busca de documentos, registros que pertencem ou não ao objeto de pesquisa estudado, aos quais são explorados para encontrar informações úteis para o entendimento e análise do problema.

Quanto ao universo da pesquisa, foi definida a $3^{\circ}$ temporada do programa MasterChef Profissionais de 2018, transmitido pela emissora de TV Rede Bandeirantes no seu período de veiculação, que aconteceu entre 21 de agosto a 11 de dezembro de 2018 e, também, a plataforma digital Twitter (no mesmo período), a fim de verificar o que há de interatividade entre o programa transmitido na televisão com as redes sociais. O talent show em questão será analisado como um todo, ou seja, os episódios do programa não serão analisados individualmente, pois o intuito da pesquisa não será quantificar quantas vezes foi identificado o resultado, mas sim se ele existe.

O Twitter anteriormente citado fez parte do universo desta pesquisa durante o período de exibição do MasterChef Profissionais por ser a rede social de maior destaque e mais utilizada pela emissora para provocar a interatividade com seus telespectadores (LAREDO, 2018). A plataforma foi analisada a partir do que é exibido na televisão e não direto no site, a fim de resolver os objetivos propostos na presente pesquisa, que posteriormente passaram a ser as categorias de análise do presente artigo, que são: 1) Classificar o tipo de interação utilizado na $3^{\circ}$ temporada do programa MasterChef Brasil profissionais; 2) Identificar o nível de interatividade utilizado na $3^{\circ}$ temporada do programa; 3) Classificar o programa de acordo com as possibilidades de interação com o Twitter; e 4) Encontrar no MasterChef profissionais as possibilidades de interação que o Twitter oferece.

No próximo item, será apresentado com mais detalhes o programa MasterChef Brasil, a fim de evidenciar e contextualizar a temática do presente artigo.

\section{MasterChef Brasil}

Tendo em vista o cenário apresentado, o programa MasterChef Brasil, talent show de competição culinária da emissora Rede Bandeirantes, vem integrando cada vez mais as telas (televisão e internet) e, instigado a interatividade com seus telespectadores. O programa foi lançado em 1990 pela emissora BCC, no Reino Unido, com um formato bem diferente do que é exibido atualmente. Após ficar restrito durante um bom tempo ao mercado inglês, em 2005 o programa foi relançado e desde então alcançou o mundo, sendo atualmente exibido por emissoras de outros 40 países, onde chegou ao Brasil somente em 2014 fazendo sua estreia na emissora de TV aberta Rede Bandeirantes (CASTRO, 2015). 
Research, Society and Development, v. 9, n.1, e94911599, 2020

(CC BY 4.0) | ISSN 2525-3409 | DOI: http://dx.doi.org/10.33448/rsd-v9i1.1599

Neste talent show, os competidores têm seus pratos avaliados por três jurados, sendo eles Érick Jacquin, Henrique Fogaça e Paola Carosella, chefs profissionais que experimentam e deliberam o prato vencedor e o eliminado. Ainda que a responsabilidade pela escolha do vencedor não seja do telespectador, as redes sociais, especialmente o Twitter, faz com que a interação dos fãs o faça ser um dos programas mais comentados na ambiência digital SAGRILLO, 2017).

Diante deste cenário, desde seu início o programa ganhou força nas redes sociais, onde os telespectadores do programa comentam e interagem fielmente. Em 2017, "o MasterChef Brasil foi o programa de TV aberta mais comentado no Twitter, na semana de 5 a 11 de junho, no ranking Kantar Twitter TV Ratings (KTTR), responsável por gerar 14,4 milhões de impressões e 92,4 mil tweets. Logo, é perceptível a grande repercussão que o programa tem na internet e o quanto os seus fãs interagem em tempo real da transmissão do programa nas redes sociais.

A grande percepção do MasterChef Brasil, perante a outros programas existentes da mesma temática, é justamente o entretenimento que a atração oferece ao seu público, que vai além do ato de só assistir o programa, mas também de permitir que o telespectador se sinta parte do produto, tendo em vista, que do início ao fim da transmissão o telespectador é convidado a acessar as redes sociais, site e aplicativo do programa diversas vezes através de mensagens que passam na tela da TV. Neste caso, alguns tweets que utilizam a \#MasterchefBR, tag oficial do programa, são selecionados e podem vir aparecer na tela da televisão durante a transmissão dos episódios.

\subsection{Resultados}

Para facilitar a compreensão da análise dos resultados e discussões, foram abordadas questões como o tipo, os níveis, as possibilidades e as formas de interação entre a primeira e segunda tela a partir da veiculação da terceira temporada do programa MasterChef Brasil profissionais.

\subsection{Tipos de interação do MasterChef Profissionais}

A partir das classificações de interatividade estabelecidas por Reisman (2002) apud Montez e Becker (2005, p.35), que são reativo, coativo e pró-ativo, percebeu-se que a mais utilizada foi a reativa conforme o quadro 5, pois está associada a um nível que possibilita a 
Research, Society and Development, v. 9, n.1, e94911599, 2020

(CC BY 4.0) | ISSN 2525-3409 | DOI: http://dx.doi.org/10.33448/rsd-v9i1.1599

interação do telespectador através de opções que são proporcionadas pela própria emissora.

Quadro 5: Tipo de interação utilizada pelo programa MasterChef Brasil profissionais

\begin{tabular}{|l|l|l|l|}
\hline Tipo de interação & \multicolumn{1}{|c|}{ Reativa } & Coativa & Pró-Ativa \\
\hline Utilizada no programa & \multicolumn{1}{|c|}{ X } & & \\
\hline Justificativa & $\begin{array}{l}\text { Através das redes sociais e inserção de } \\
\text { tweets durante a transmissão do } \\
\text { programa. }\end{array}$ & & \\
\hline
\end{tabular}

Fonte: Elaboração Própria baseado em Reisman (2002) apud Montez e Becker (2005).

Diante deste cenário, o programa MasterChef pode ser considerado um programa interativo, principalmente em uma época que se fala muito em convergência. Tanto as redes sociais do programa como de seus telespectadores, principalmente no Twitter, acompanham em tempo real a transmissão do programa e participam através da hashtag oficial "\#MasterChefBR", que evidencia o convite para o envio de mensagens, fotos, vídeos e GIFs, referente às situações que estão acontecendo durante sua veiculação. Entretanto, ainda que interativo, o público não apresenta influência na estrutura e continuidade do programa e, portanto, se justifica a classificação de interação reativa. Neste tipo de interação é o programa quem vai determinar e dar as opções de participação do seu telespectador, o que vai ao encontro do que Primo (2000) já dizia, onde na interação reativa não há autonomia para o telespectador, mas sim um conjunto de alternativas que já estão preestabelecidas, neste caso, pela própria produção do programa.

Diante deste contexto, mesmo que não haja interferência sob o produto televisivo, ao se enxergar como parte do produto que está sendo transmitido, o telespectador passará a criar um vínculo com o programa, acarretando naquilo que Jenkins (2009) já dizia, no qual os conteúdos e informações passam a ser compartilhados em diferentes mídias a partir da participação e envolvimento do telespectador, bem como acontece durante todos episódios do programa.

\subsection{Níveis de interatividade do MasterChef}

Já a segunda etapa foi identificar o nível de interatividade que é utilizado pelo programa, classificados entre 0 e 7, conforme cita Lemos (1997). Estes níveis representam o progresso interativo que aconteceu durante a história e linha cronológica da televisão. O nível 0, por exemplo, representa a televisão em seu início, ainda em preto e branco, com pouquíssimos canais e possibilidades de interação. Já no nível 7, o mais abrangente e atual 
entre os outros níveis, possibilita que além do transmissor, o telespectador também possa gerar conteúdo e, portanto, se assemelha com o que acontece no século XXI na internet, onde a produção de conteúdo pode vir de qualquer pessoa. Neste sentido, o conteúdo que é veiculado na TV, também poderá ser consumido, adaptado ou compartilhado em outras plataformas.

A partir disso, o nível de interatividade da $3^{\circ}$ temporada do MasterChef BR Profissionais é o 4, pois retrata o momento em que o telespectador passa a participar do conteúdo que está sendo transmitido a partir de possibilidades/ferramentas oferecidas pela emissora, tal como ocorre no MasterChef profissionais, quando o usuário é convidado a participar de enquetes e tuitar utilizando a hashtag oficial do programa. Ainda que esteja participando de forma ativa, o telespectador não terá controle e tão pouco autonomia sob o conteúdo do programa e, isso vai ao encontro do que Lemos (1997, p. 36) já dizia, que neste nível, "o telespectador ainda não tem controle total sobre a programação, ele apenas reage a impulsos e caminhos pré-definidos pelo transmissor, e isso ainda não é TV interativa". Tal contexto vai ao encontro do tipo de interação que acontece entre a televisão e o telespectador, anteriormente identificada como reativa. Lemos (1997), dentre suas teorias, já considerava que uma interação reativa possivelmente seria identificada no e nível 4 de interatividade, bem como acontece no programa MasterChef Profissionais.

\subsection{Possibilidades de interação}

A terceira etapa foi classificar o programa de acordo com as possibilidades de interação com o Twitter, a partir de 12 estratégias propostas por Sagrillo (2017), sendo elas: Convite ao acesso a ambiente; Conexão com redes sociais digitais; Disponibilização de chats on-line; Apelo a hashtag; Oferta de avatares; Disponibilização de aplicativos; Oferta de check-in dos programas; Criação de enquetes; Proposta de desafios; Criação de concursos; Disponibilização de compras on-line; e Inserção de espaços interativos.

Durante a análise, foram então identificadas as possibilidades de interação que são utilizadas no programa, em quais episódios apareceram e de que forma isso se evidencia na televisão. A primeira possibilidade identificada foi o convite ao acesso de ambientes, que esteve presente em todos os episódios da temporada, das seguintes formas: na fala da apresentadora, no canto superior direito através da hashtag do programa e no canto inferior esquerdo da tela da televisão com o username da conta oficial do MasterChef BR no Twitter.

Partindo deste cenário e em decorrência da primeira possibilidade de interação 
apresentada, a segunda e a terceira encontradas no programa são a Conexão com as redes sociais digitais e o apelo a hashtag, na qual ambas acontecem a partir da mesma perspectiva: o uso da hashtag. Nestas possibilidades, os telespectadores além de serem convidados a acessar as redes sociais do programa e a utilizar a hashtag oficial no Twitter, eles participam do produto televisual que estão consumindo, comentando em tempo real aquilo que está sendo transmitido na televisão. E ainda, posteriormente, alguns tweets são escolhidos pela produção e inseridos durante a transmissão do programa, conforme mostra a figura 2. Entretanto, é importante ressaltar que estes tweets escolhidos e inseridos durante a transmissão do programa não obedecem a uma ordem cronológica do que está acontecendo em tempo real na televisão, portanto, não vão ao encontro com o que está sendo visto pelo telespectador, mas sim do que já passou.

A quarta possibilidade encontrada foi sobre a criação de enquetes, ofertadas pela produção do programa que questionou: quem fica, qual equipe deve vencer a prova (equipe amarela, vermelha ou azul) ou até mesmo quem sai. Nesta temporada do programa, a criação de enquete aconteceu no episódio 11 através da fala da apresentadora Ana Paula Padrão, que questionou em uma prova de equipes a “\#QuemFica?”, convidando então os telespectadores a votar no Twitter oficial do MasterChef BR, conforme ilustrado na figura 3, no próximo item da análise. Neste sentido, o telespectador é convidado a navegar no Twitter do programa para votar e só assim terá acesso ao resultado, já que o mesmo não foi divulgado na TV.

Por fim, a quinta e última possibilidade encontrada durante o programa foi a de proposta de desafios. Embora não haja nenhuma grande recompensa, a proposta de desafio se evidencia em todos os episódios quando os telespectadores são convidados a acessarem as redes sociais do programa e tuitarem utilizando a hashtag oficial MasterChef, podendo então, ver seu tweets na tela da televisão durante a veiculação do mesmo.

Tendo em vista as 12 possibilidades propostas pela Sagrillo (2017) e citadas anteriormente, o quadro 6 exemplifica todas possibilidades que foram encontradas (em amarelo) durante a transmissão do programa e as que não foram identificadas (em cinza).

Quadro 6: Possibilidades de interação nos episódios do MasterChef brasil profissionais

\begin{tabular}{|c|c|c|}
\hline Possibilidades & Episódio & Como apareceu \\
\hline Convite ao acesso de ambientes & Todos & $\mathrm{Na}$ fala da apresentadora e na tela da TV \\
\hline $\begin{array}{c}\text { Conexão com as redes sociais } \\
\text { digitais }\end{array}$ & Todos & $\begin{array}{l}\text { Através de tweets veiculados durante a } \\
\text { transmissão do programa }\end{array}$ \\
\hline Disponibilização de chats on-line & Nenhum & Não identificado \\
\hline Apelo a hashtag & Todos & Na fala da apresentadora e na tela da TV \\
\hline
\end{tabular}


Research, Society and Development, v. 9, n.1, e94911599, 2020

(CC BY 4.0) | ISSN 2525-3409 | DOI: http://dx.doi.org/10.33448/rsd-v9i1.1599

\begin{tabular}{|c|l|c|}
\hline Oferta de avatares & Nenhum & Não identificado \\
\hline Oferecimento de aplicativos & Nenhum & Não identificado \\
\hline Oferta de check-in em programas & Nenhum & Não identificado \\
\hline Criação de enquetes & 11 & $\begin{array}{c}\text { Na fala da apresentadora através de } \\
\text { hashtag }\end{array}$ \\
\hline Proposta de desafios & Todos & Tuitar utilizando a hashtag oficial \\
\hline Criação de concursos & Nenhum & Não identificado \\
\hline $\begin{array}{c}\text { Disponibilização de compras on- } \\
\text { line }\end{array}$ & Nenhum & Não identificado \\
\hline Inserção de espaços interativos & Nenhum & Não identificado \\
\hline
\end{tabular}

Fonte: Elaboração Própria baseado em Sagrillo (2017).

Vale ressaltar que embora algumas das possibilidades não tenham sidas encontradas durante a análise, elas se limitam apenas a pesquisa da terceira temporada profissionais do MasterChef Brasil e não para as demais.

\subsection{Formas de interação do Twitter com a televisão}

A última e quarta etapa foi encontrar no MasterChef profissionais formas de interação que o Twitter oferece. Para que fosse viável concluir a análise, foi necessário identificar todas as possibilidades que o programa e a rede social oferecem de interatividade para seus telespectadores e usuários, para que assim, posteriormente, fosse feito um cruzamento com os resultados obtidos.

As utilizações desses recursos interativos são positivas para a conexão e integração do conteúdo que é transmitido na televisão e compartilhado pelo telespectador, e também serve como um suporte para medir a audiência e aceitabilidade de um programa. Inclusive, inúmeros programas, das mais variadas emissoras, estão aderindo à integração das telas para se conectarem cada vez mais com seus usuários e, isso se evidencia no MasterChef profissionais, que possibilita várias formas de interagir com sua audiência.

Dentre as possibilidades de interação encontradas no Twitter, observou-se que na terceira temporada do programa, os telespectadores foram convidados a tuitar em seu perfil utilizando a hashtag oficial e visitar as redes sociais do programa (Facebook e Instagram). Alguns tweets de usuários que seguiram a chamada do talent show e utilizaram a hashtag, foram veiculados durante a transmissão do episódio. Ainda, através dos tweets, o programa, quando exibido na TV, conta com um marcador que contabiliza em tempo real o número de vezes que a hashtag do programa está sendo citada, bem como acontece nos trendings topics do Twitter. Além disso, em algumas falas da apresentadora, o telespectador foi convidado a 
participar de enquetes criadas no Twitter.

Essa integração a partir das possibilidades de interação entre o programa e o Twitter vai ao encontro do que Sagrillo (2017) reflete em sua tese, onde ela diz que a participação dos telespectadores auxilia a definir quem são os participantes favoritos, que em consequência, aumentam a audiência do programa, mas que a interação oferecida pela emissora, inclusive as enquetes, não alteram os resultados e andamento do mesmo.

\section{Considerações Finais}

A partir destas definições e analises em torno da interatividade existente entre o programa e seus telespectadores, foi possível identificar o MasterChef como um programa que utiliza a interação reativa e encontra-se no nível 4 de interatividade, já que todas as possibilidades oferecidas aos seus telespectadores são pré-determinadas pela produção, diferente do que já acontece em outros programas televisivos, tal como o Big Brother Brasil, onde o público tem a possibilidade de interferir na continuidade do reality show através da votação popular que define qual participante deixará ou permanecerá no jogo. Sabendo que a interatividade já era executada por outros programas, tal como o Você Decide e BBB, é importante ainda ressaltar que os programas televisivos foram se adaptando por conta dos avanços tecnológicos.

Entretanto, para que tal interatividade aconteça entre o programa e seus telespectadores, que neste contexto participam através de suas redes sociais, ainda foram utilizadas 12 estratégias de possibilidades de interação voltadas para o que acontece na televisão e possibilita a interatividade do telespectador no Twitter. Durante a análise, foi possível identificar que entre as 12 estratégias propostas, apenas 5 foram oferecidas aos seus telespectadores, tais como: Convite ao acesso a ambientes; Conexão com redes sociais digitais; Apelo a hashtag; Criação de enquetes; e Propostas de desafios. As propostas identificadas, com exceção da criação de enquetes, estiveram presentes em todos episódios, evidenciando um convite para que os telespectadores se sintam parte do produto que está sendo veiculado e logo, participem através de seu Twitter comentando o que está acontecendo durante a transmissão do programa.

Já as estratégias de disponibilização de chats on-line, oferta de avatares, disponibilização de aplicativos, oferta de check-in dos programas, criação de concursos, disponibilização de compras on-line e inserção de espaços interativos, não foram identificadas nesta temporada, evidenciando que o MasterChef, ainda que interativo, não utiliza de maneira 
eficaz e completa todas as possibilidades que poderiam lhe render um melhor relacionamento e engajamento com seus telespectadores.

Ainda neste contexto, enquanto as estratégias citadas anteriormente fazem referência as possibilidades do que pode acontecer no programa, o $4^{\circ}$ e último objetivo da pesquisa teve como intuito mostrar as possibilidades de interatividade que existem no Twitter, a rede social que mais se destacou no quesito participação e aproximação do telespectador. Das 13 possibilidades encontradas no Twitter, apenas 6 (twittar, favoritar, criar enquetes e utilizar hashtag, visitas as redes sociais e o contador de tweets) cruzam com as possibilidades de interatividade que são ofertadas durante o programa, enquanto as outras 9 (iniciar uma conversa na caixa de tweet, dar follow e unfollow, responder tweets, retwittar, favoritar e mencionar) não são exploradas pelo programa. Ainda, é importante ressaltar que embora não seja uma prática do MasterChef utilizar todas possibilidades encontradas, elas não deixam de acontecer no Twitter entre os telespectadores e usuários da rede social.

Neste contexto todo, foi possível ainda perceber que nem todas as possibilidades fomentam a integração entre as telas, mas sim a interatividade/participação dos telespectadores, o que os tornam participantes ativos ao invés de participantes passivos. Além disso, diante de tantas possibilidades e o MasterChef ser um programa pioneiro em utilizar o Twitter para dar em primeira mão resultados através das redes sociais, a produção do programa poderia pensar em novas estratégias e/ou inovações, buscando aumentar o tipo de interação (de reativa para coativa) e a escala do nível 4, possibilitando assim novas formas e maiores espaços de interação para que o telespectador então possa participar, interferir, se incluir e definir mais coisas dentro do programa.

Conforme a análise, foi identificado que há espaços e até mesmo oportunidades para aperfeiçoar a integração entre as telas, tal como o resultado das enquetes criadas no Twitter. O convite para a participação do telespectador acontece na televisão, através da fala da apresentadora e a votação acontece no Twitter oficial do programa, porém o resultado da enquete fica restrito e visível apenas na rede social, ou seja, não é divulgado na TV durante a veiculação do mesmo. Da mesma forma, acontecem com os tweets que são inseridos durante a transmissão, eles destoam do que esta acontecendo no programa, pois não estão sincronizados com o conteúdo. Além disso, há tantas outras possibilidades de interação apresentadas por Sagrillo (2017) que não foram encontradas durante a análise e poderiam trazer mais repercussão e interação para o programa.

Logo, o MasterChef Brasil surge como uma oportunidade e/ou experiência de acompanhar um programa que integra diversas plataformas, tais como a televisão e as redes 
(CC BY 4.0) | ISSN 2525-3409 | DOI: http://dx.doi.org/10.33448/rsd-v9i1.1599

sociais, evidenciando potenciais ferramentas que auxiliam na participação do telespectador e no aumento da audiência do programa, mas que ainda peca perante as inúmeras possibilidades que são disponibilizadas por outros meios e que poderiam otimizar o relacionamento e a integração entre os telespectadores e o conteúdo que esta sendo veiculado na TV.

Quanto a temática, a pesquisa apresentou algumas limitações para a análise dos dados, que só puderam ser obtidos através da transmissão em tempo real pela Rede Bandeirantes (Band), já que algumas das inserções de chamadas para a interação só aconteciam pela televisão e não estavam disponíveis em outros meios de reprodução. Além do mais, o programa é relativamente atual e, portanto, ainda não há muitas pesquisas que envolvam o talent show de culinária Master Chef Brasil. E, neste sentido, fica como sugestão para futuras pesquisas compreender como essas possibilidades funcionam nas demais mídias sociais que são utilizadas pelo programa (Facebook e Instagram), ou até mesmo fazer um cruzamento entre as possibilidades do que acontece no MasterChef Amador com o MasterChef Profissionais.

\section{Referências}

Andres, F.S. (2017). \#PARTICIPE: a interatividade do fazer televisual. Cadernos de comunicação, 21 (3), 168-175.

Bardin, L. (1977). Análise de conteúdo. Lisboa: Edições 70.

Barichello, E. M. M. R. (2014). Midiatização e cultura nas organizações da contemporaneidade: o processo de midiatização como matriz de práticas sociais. In: Marchiori, M. (Org.). Contexto Organizacional Midiatizado. Academia Edu, 8, 37-43.

Bélisle, J.; Bodur, H. (2010). Avatars as Information: Perception of Consumers Based on Their Avatars in Virtual Worlds. Psychology \& Marketing, 27(8), 741-765.

Carneiro, R.G. (2012). Publicidade na TV digital: Um mercado em transformações. São Paulo: Aleph. 
Castro, T. D. (2015). Primeiro MasterChef, em 1990, era 'cerebral' e não tinha drama. Acesso em 7 de junho, em http://noticiasdatv.uol.com.br/noticia/televisao/primeiro-masterchef-em1990-era-cerebral-e-nao-tinha-drama-9119.

Ibope conecta. (2015). 88\% dos internautas veem TV e navegam na internet, diz Ibope. Acesso em 10 de junho, em https://exame.abril.com.br/tecnologia/88-dos-internautas-veemtv-e-navegam-na-internet-diz-ibope/.

Fechine, Y.; Gouveia, D.; Almeida, C.; Costa, M.; Estevão, F. (2013). Como pensar os conteúdos transmídias na teledramaturgia brasileira? Uma proposta de abordagem a partir das telenovelas da Globo. In: Lopes, M. I. V. Estratégias de transmidiação na ficção televisiva brasileira. Porto Alegre: Sulina, 19-60.

Folha de São Paulo. (2017). 'MasterChef' em números: de 5 milhões de tuítes a dez pontos no Ibope. Acesso em 27 de agosto, em https://f5.folha.uol.com.br/televisao/2017/08/confira-afinal-do-masterchef-em-numeros.shtml.

Gabriel, M. (2013). Educ @ r: a (r)evolução digital na educação. São Paulo: Editora Saraiva.

Gil, A. C. (1991). Métodos e técnicas de pesquisa social. São Paulo: Atlas.

Jenkins, H. (2009). Cultura da Convergência. São Paulo: ALEPH.

Laredo, P. (2018). O MasterChef e o engajamento da audiência na era da convergência e das mídias de funções pós-massivas. Acesso em 27 de maio, em http://labcon.fafich.ufmg.br/omasterchef-e-o-engajamento-da-audiencia-na-era-da-convergencia-e-das-midias-de-funcoes pos-massivas/.

Las casas, A. L. (2010). Marketing interativo: a utilização de ferramentas e mídias digitais. São Paulo: Saint Paul.

Lemos, A. L. M. (1997). Anjos interativos e retribalização do mundo: sobre interatividade e interfaces digitais. In: http://www.facom.ufba.br/pesq/cyber/lemos/interac.html. 
Lévy, P. (1999). “Que é o virtual?”. São Paulo: 34.

Kleina, N. (2014). Twitter libera função Estatísticas para todos os usuários. Acesso em 27 de maio, em https://www.tecmundo.com.br/twitter/61206-twitter-libera-funcao-estatisticasusuarios.htm.

Mattos, S. (1990). Um Perfil da TV Brasileira. Salvador-BA: a tarde.

Mcluhan, H. M. (1964). Os Meios de Comunicação como Extensões do Homem. São Paulo: Cultrix.

Meio e mensagem. (2017). Em seis edições, 40 marcas já passaram pelo Masterchef. Acesso em 27 de agosto, em https://www.meioemensagem.com.br/home/midia/2017/03/02/em-seisedicoes-40-marcas-ja-passaram-pelo-masterchef.html.

Michel, M. H. (2015). Metodologia e Pesquisa Científica em Ciências Sociais. São Paulo: Atlas.

Mídia dados. (2017). Mídia dados 2017. São Paulo.

Mídia dados. (2018). Mídia dados 2018. São Paulo.

Montez, C. Becker, V. (2005). TV Digital Interativa: conceitos, desafios e perspectivas para o Brasil. Florianópolis: ed. da UFSC.

Oliveira, R. (2010). Convergência Midiática: três categorias. Conexões Midiáticas. João Pessoa.

Padrão, A. P. (2015). MasterChef é sucesso no Twitter e vira referência na relação TV e redes sociais. In: O Dia. Acesso em 19 de abril, em https://odia.ig.com.br/_conteudo/diversao/televisao/2015-07-07/masterchef-e-sucesso-notwitter-e-vira-referencia-na-relacao-tv-e-redes-sociais.html. 
Research, Society and Development, v. 9, n.1, e94911599, 2020

(CC BY 4.0) | ISSN 2525-3409 | DOI: http://dx.doi.org/10.33448/rsd-v9i1.1599

Pazin, S. (2017). Como a combinação TV + web potencializa campanhas. Entrevista concedida ao site negócios RPC. Acesso em 27 de setembro, em https://www.negociosrpc.com.br/deolhonomercado/midia/como-a-combinacao-web-tvpotencializa-campanhas/.

Primo, A. (2000). Interação mútua e reativa: uma proposta de estudo. In: Famecos: mídia, cultura e tecnologia. Porto Alegre.

Recuero, R. (2009). Redes sociais na internet. Porto alegre: Sulina.

Rede Bandeirantes. (2019). MasterChef Profissionais. São Paulo.

Rede globo. (2019). Big Brother Brasil. Rio de Janeiro.

REDE GLOBO. (2019). Você Decide. Rio de Janeiro.

Reisman, R. R. (2002). Rethinking Interactive TV - I want my Coactive TV. Teleshuttle Corporation. Acesso em 8 de outubro, em http://www.teleshuttle.com/cotv/CoTVIntroWt Paper.htm.

Silva, L. B. (2015). A construção da celebridade em talent shows: uma análise dos programas The X Factor (EUA e Reino Unido) e The Voice (EUA e Brasil). Rio de Janeiro: UFRJ Programa de Pós-Graduação em comunicação e cultura.

Stauer, J. (1992). Definindo Realidade Virtual: Dimensões Determinando Telepresença. Jornal de Comunicação.

Strutzel, T. (2015). Presença Digital: estratégias eficazes para posicionar sua marca pessoal ou corporativa na web. Rio de Janeiro: Alta Books.

Teixeira, L. H. P. (2008). Televisão digital: interação e usabilidade. 150 f. Dissertação (mestrado) - Universidade Estadual Paulista, Faculdade de Arquitetura, Artes e Comunicação. Acesso em 27 de setembro, em http://hdl.handle.net/11449/89489. 
Toffler, Alvin. (1980). A terceira onda. Rio de Janeiro: Record.

Torres, C. (2009). A Bíblia do Marketing Digital: Tudo o que você queria saber sobre marketing e publicidade na internet e não tinha a quem perguntar. São Paulo: Novatec.

Tunstill, S. (2016). A televisão está mudando. Acesso em 10 de junho, em https://gauchazh.clicrbs.com.br/cultura-e-lazer/tv/noticia/2016/12/a-televisao-esta-mudandodiz-simon-tunstill-8678807.html.

Wolton, D. (2007). Internet, e depois? Uma teoria crítica para as novas mídias. 2ed. Trad. Isabel Crosseti. Porto Alegre: Sulina.

\section{Porcentagem de contribuição de cada autor no manuscrito}

Matheus Silveira Jardim - 50\%

Angélica Pereira Moreira - 50\% 